\title{
ОТСУТСТВИЕ ВЗАИМНОГО СОГЛАСИЯ СТОРОН КАК УСЛОВИЕ ПРИЗНАНИЯ СДЕЛКИ ОСПОРИМОЙ В СОВРЕМЕННОМ ДОГОВОРНОМ ПРАВЕ ВЕЛИКОБРИТАНИИ
}

\section{LACK OF MUTUAL ASSENT \\ AS A CONDITION FOR RECOGNIZING A CONTRACT AS VOIDABLE IN MODERN ENGLISH CONTRACT LAW}

A. Kozlov

Summary. This article analyzes in detail the lack of mutual assent of the parties as a factor of invalidity of the transaction in English contract law. The author identifies three main forms of the lack of mutual assent of the parties to the contract: 1) mistakes as to contractual realities; 2) misrepresentation; 3) exercise of duress and undue influence on the counteragent. The article describes each of the above forms, citing specific examples from the court practice of the United Kingdom. The conclusion is made about the influence of the fundamental principles of English contract law on the understanding of the lack of mutual assent as a concept.

Keywords: English contract law, lack of mutual assent, mistake, contractual realities, misrepresentation, duress, undue influence, counteragent.

\author{
Козлов Антон Гордеевич \\ Преподаватель, ФГБОУ ВО «Государственный \\ университет управления», г. Москва \\ antonkozlov3000@yandex.ru
}

Аннотация. В данной статье подробно анализируется отсутствие взаимного согласия сторон договора как фактор недействительности сделки в договорном праве Великобритании. Автор выделяет три основных формы отсутствия взаимного согласия сторон договора: 1) ошибки относительно договорных реалий; 2) введение контрагента в заблуждение; 3) оказание давления и неправомерного влияния на контрагента. В статье дано описание каждой из вышеуказанных форм с приведением конкретных примеров из практики судов Великобритании. Сделан вывод о влиянии фундаментальных принципов договорного права Великобритании на понимание концепции отсутствия взаимного согласия сторон.

Ключевые слова: право договоров Великобритании, отсутствие взаимного согласия, ошибки в договорах, введение в заблуждение, давление, неправомерное влияние, контрагент.
B соответствии с нормами договорного права Великобритании при оценке действительности договоров судьи должны определить, согласились ли стороны заключить сделку добровольно и с полным пониманием ее смысла. Отсутствие взаимного согласия сторон может выражаться в 1) возникновении ошибок относительно различных договорных реалий, 2) введении контрагента в заблуждение и 3) оказании давления или неправомерного влияния на контрагента. Отсутствие взаимного согласия сторон, выраженное в любой из вышеперечисленных форм, является достаточным условием для признания сделки оспоримой. Оспоримые сделки могут быть расторгнуты по желанию одной из сторон или признаны ничтожными по результатам судебного разбирательства. [2]

Наиболее частыми видами ошибок, встречающихся в договорном процессе, являются ошибочное понимание конкретных условий договора и ошибки относительно личности контрагента. Ошибочное понимание договорных реалий обеими сторонами сделки позволяет судам признать существование «взаимной ошиб- ки» («mutual mistake»), в то время как в тех случаях, когда только одна сторона сделки ошибается в отношении фактического содержания договора или личности контрагента, суды говорят об «односторонней ошибке» («unilateral mistake»).

\section{Взаимная ошибка}

Когда стороны существенно расходятся в понимании конкретных условий договора и не знают об этом, суд должен постановить, что стороны преследуют разные цели при исполнении договора («acting at cross-purposes»). Возникновение подобных ситуаций может быть обусловлено наличием расплывчатых или двусмысленных формулировок в соглашении, а также принципиально разными точками зрения сторон на факты объективной реальности. Так, например, в классическом деле Raffles $v$ Wichelhaus (1864) продавец полагал, что груз хлопка отправится к покупателю на корабле SS Peerless, в то время как покупатель готовился принять груз, транспортируемый на другом корабле с таким же названием. При обнаружении вза- 
имной ошибки судьи действуют в полном соответствии с принципом свободы договора: необходимо признать, что мнение каждой из сторон может быть сочтено разумным, и постараться сделать все возможное, чтобы вынести окончательное решение в пользу того мнения, которое обеспечит исполнение сделки на наиболее выгодных условиях для всех ее участников. Тем не менее, когда расхождение во мнениях признается не подлежащим исправлению, судьи объявляют договор недействительным ab initio (т.е. с момента его заключения).

\section{ОАНОсторОНняЯ ОшИбКа

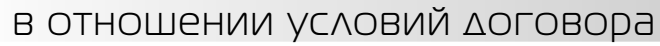

Если одна из сторон допустит явную ошибку в формулировании или понимании условий договора, и такая ошибка станет известна другой стороне, последняя должна предупредить об ошибке своего контрагента. В противном случае суд признает соглашение недействительным. При решении вопроса о том, могут ли стороны распознать ошибки в договорах, судьи принимают во внимание стандарты разумности (за критерий разумного поведения берется поведение «обычного разумного человека» в анализируемой ситуации), а также профессиональный статус сторон (например, ошибки в понимании коммерческих реалий договора должны быть очевидны для всех предпринимателей). Так, в деле Hartog v Colin \& Shields (1939) суд постановил, что бизнесмен, много лет занимавшийся разведением зайцев и продажей их шкур, был обязан распознать опечатку в расчете цены крупной партии заячьих шкур. Если «обычный разумный человек» или бизнесмен не укажут своему контрагенту на очевидные для них ошибки, то контрагент имеет право настоять на своем толковании тех договорных условий, в которых была допущена ошибка.

\section{ОАНОСТОРОНняЯ ОШИбКа в отношении ^ичности контрагента}

Согласно общему правилу, суд обязан признать соглашение недействительным в случае, когда одна из сторон ошибается в отношении личности своего контрагента. Если одна из сторон договора, действуя в мошеннических целях, обманом заставляет своего контрагента признать ее другим физическим или юридическим лицом, договор может быть расторгнут по требованию обманутой стороны. Так, в деле King's Norton Metal Co Ltd v Edridge, Merrett \& Co Ltd (1897) через подставное лицо была создана компания, которая занималась скупкой товаров в кредит с целью их последующей перепродажи по более высоким ценам. Суд удовлетворил иск кредиторов, не получивших исполнения своих требований от компании-должника, после установления мошеннического характера деятельности последней.
Следует особо отметить, что во многих видах сделок (наиболее показательным примером является розничная продажа товаров в универмагах) личность контрагента не имеет значения. Вышеуказанное правило о признании соглашения недействительным применяется в тех случаях, когда сторона соглашается заключить договор только с определенным физическим или юридическим лицом (таким образом, ошибочная идентификация личности контрагента лишает сделку ее существенного смысла).

Когда сделки заключаются при личном присутствии сторон, предполагается, что сторона, допустившая ошибку, имеет дело с лицом, которое физически присутствует перед ней.

Когда договор составлен в письменной форме, предполагается, что сторона, допустившая ошибку, имеет дело с контрагентом, имя которого указано в тексте договора. Это правило применяется также в тех случаях, когда весь процесс переговоров по сделке осуществляется в письменной форме, но фактически договор заключается при личной встрече сторон.

\section{Совместная ошибка сторон Аоговора}

Неправильное понимание фактов объективной реальности сторонами договорного процесса может обусловить несовпадение их волеизъявлений и привести к возникновению так называемой «совместной ошибки» («common mistake»).

Современная доктрина совместной ошибки была разработана судьями Апелляционного суда Ее Величества, которые постановили, что стороны могут расторгнуть договор, если будут выполнены следующие четыре условия: 1) стороны верят в существование определенных договорных реалий, но эти реалии не существуют на самом деле; 2) ни одна из сторон не несет ответственности за обеспечение существования данных договорных реалий; 3) было бы ложным утверждать, что данные договорные реалии прекратили свое существование по вине какой-либо из сторон; 4) тот факт, что данные договорные реалии не существуют на самом деле, делает исполнение договора объективно невозможным (наиболее показательными примерами являются договоры купли-продажи таких товаров, которые никогда не существовали или прекратили свое существование) или лишает сделку ее первоначального коммерческого смысла. Следует особо отметить, что в приведенном выше перечне термин «договорные реалии» следует понимать как а) предмет договора; б) существенные условия договора; в) фактические обстоятельства совершения сделки. Так, например, в деле Couturier v Hastie (1856) стороны 
заключили договор купли-продажи зерна в то время, когда корабль, груженный зерном, находился в пути от продавца к покупателю. При этом стороны договора не были осведомлены о том факте, что в момент заключения сделки зерно уже начало портиться, и капитан грузового судна принял решение о его продаже третьей стороне до прибытия в пункт назначения. [5]

\section{Введение контрагента в заблужАение}

Согласно общему правилу, если одна из сторон договора делает ложное утверждение о прошлом или настоящем факте, имеющем отношение к сделке, то данная сторона вводит контрагента в заблуждение. Определенные утверждения о фактах следует отличать от простого выражения мнений в процессе переговоров. Так, в деле Bissett v Wilkinson (1927) суд посчитал утверждение одной из сторон о том, что земельный участок пригоден для выпаса 2000 овец, выражением личного мнения, а не утверждением о факте, так как данная сторона не обладала профессиональными знаниями в сфере животноводства.

Если сторона договора передает своему контрагенту информацию, полученную от третьих лиц, такая сторона будет нести гражданско-правовую ответственность за введение контрагента в заблуждение только в случае преднамеренного искажения фактов, предоставленных первичным источником. Если данная сторона интерпретирует полученную информацию и предоставляет ее контрагенту в качестве собственного утверждения об определенном факте, гражданско-правовая ответственность наступает в том случае, когда такое заявление оказывается ложным.

Умолчание об определенных фактах приравнивается к введению контрагента в заблуждение в тех случаях, когда характер договора презюмирует наличие доверительных отношений между сторонами (это относится к договорам страхования, а также к договорам купли-продажи, которые подразумевают ответственность производителей товаров перед потенциальными покупателями).

Согласно судебной практике, сторона договора может быть привлечена к гражданско-правовой ответственности за введение контрагента в заблуждение посредством конклюдентного поведения.

Закон «О введении в заблуждение», принятый Парламентом Соединенного Королевства в 1967 году, дает определения трех видов утверждений о фактах, приводящих к введению контрагента в заблуждение: 1) мошенническое (преднамеренное) искажение фактов, совершаемое стороной договора, которая либо а) изначально знает о ложности фактов, либо б) безразлично относится к тому, являются ли данные факты истинными или ложными; 2) искажение фактов вследствие проявленной небрежности, совершаемое стороной договора, которая безразлично относится к тому, являются ли данные факты истинными или ложными, и при этом характер договора презюмирует наличие доверительных отношений между сторонами; 3) искажение фактов вследствие добросовестного заблуждения, совершаемое стороной, которая не знает и не может знать о ложности той информации, которую она передает контрагенту. Согласно положениям Закона, в случае мошеннического искажения фактов пострадавшая сторона может потребовать признать договор недействительным с момента его заключения (т.е. аннулировать результаты деятельности, осуществленной в целях исполнения обязательств по договору и восстановить status quo сторон) и компенсировать убытки, понесенные в результате предоставления заведомо ложной информации. В случае искажения фактов вследствие проявленной небрежности, выбор между признанием договора недействительным с момента его заключения и компенсацией убытков осуществляется на усмотрение суда. Искажение фактов вследствие добросовестного заблуждения предоставляет пострадавшей стороне право на компенсацию убытков только в том случае, когда ложная информация была включена в договор в качестве существенного условия; в противном случае, пострадавшая сторона может потребовать компенсации убытков. [1]

\section{Оказание Аавления на контрагента}

Сторона может потребовать расторжения договора в судебном порядке в случае, если сделка была заключена в результате принуждения со стороны контрагента. Согласно судебной практике, принуждение может принимать форму а) угроз личности контрагента; б) угроз причинения материального ущерба контрагенту или в) оказания экономического давления на контрагента.

а) Угрозы личности контрагента включают угрозы применения насилия, а также угрозы лишения свободы. Такие угрозы могут быть высказаны либо в адрес самого контрагента, либо в адрес близких ему людей или его сотрудников. Более того, данные угрозы, высказанные в отношении человека, совершенно незнакомого контрагенту, будут приравнены судом к угрозам личности контрагента, если удастся доказать, что заключение контрагентом нежелательной сделки является единственным способом предотвратить причинение вреда незнакомому лицу.

б) Угрозы причинения материального ущерба контрагенту включают угрозы повреждения или унич- 
тожения имущества контрагента, а также угрозы незаконного изъятия товаров контрагента из оборота или незаконной задержки сроков доставки таких товаров.

в) Экономическое давление возникает в ситуациях, когда одна из сторон угрожает отказаться от исполнения своих обязательств по договору, если контрагент не согласится исполнить ее требования. При этом отказ стороны от исполнения своих обязательств по договору может в достаточной степени ухудшить финансовое положение ее контрагента или даже привести его к банкротству. В то же время предъявляемые требования должны быть коммерчески необоснованными (т.е. они должны выходить за рамки обычной конкурентной борьбы на капиталистических рынках). Так, в деле Kolmar Group AG v Traxpo Enterprises Pvt Ltd (2010) продавец метанола после заключения договора купли-продажи внезапно заявил своему контрагенту, что готов продать метанол только по значительно завышенной цене. Контрагент, который был связан обязательством поставить большую партию метанола третьему лицу и не имел возможности заказать метанол у другого продавца, был вынужден согласиться на невыгодную сделку и понес значительные убытки. Суд признал действия продавца метанола оказанием экономического давления на контрагента. [3]

\section{Оказание неправомерного в^ияния на контрагента}

Сторона может потребовать расторжения договора в судебном порядке в случае, если сделка была заключена в результате оказания неправомерного влияния со стороны контрагента. Современная судебная практика проводит четкое различие между а) фактическим неправомерным влиянием и б) презюмируемым неправомерным влиянием.

а) Суд устанавливает факт оказания неправомерного влияния в том случае, если истец предоставляет доказательства 1) существования доверительных отношений между ним и контрагентом; 2) злоупотребления доверием со стороны контрагента с целью принуждения к заключению невыгодной сделки.

б) Определенные виды личностных отношений между сторонами договора (например, отношения между родителем и ребенком, опекуном и подопечным, адвокатом и клиентом, врачом и пациентом и т.д.) порождают презумпцию оказания неправомерного влияния на контрагента в случае возникновения гражданско-правовых споров. Чтобы опровергнуть эту презумпцию, ответчик должен доказать, что до заключения договора истец получил консультацию относительно сути соглашения от независимого и профессионально компетентного лица, которое осведомлено обо всех фактических обстоятельствах сделки. Так, в деле Barclay's Bank PLC v O’Brien (1994) муж убедил жену выступить гарантом обеспечения исполнения обязательств его компании перед банком, сообщив ей существенно заниженную сумму превышения кредита. Суд постановил, что на жену было оказано неправомерное влияние, так как представители банка не смогли обеспечить ей независимую юридическую консультацию перед заключением сделки. [4]

На основании вышесказанного можно сделать вывод о том, что отсутствие такого важного элемента договора как взаимное согласие сторон автоматически обусловливает оспоримый характер сделки в современном договорном праве Великобритании. Соблюдение принципа обязательной силы договора становится возможным благодаря наличию комплексного правового механизма, призванного компенсировать вред, причиненный пострадавшей стороне. При этом принцип свободы договора не позволяет признать договор недействительным без проведения судебного разбирательства, что служит гарантией сохранения договорных отношений до обнаружения не подлежащего исправлению фактора недействительности сделки.

\section{ЛИТЕРАТУРА}

1. Andrew Burrows. A Restatement of the English Law of Contract [Пересмотр права договоров Великобритании]/0xford University Press; 1st edition, 2016. $297 \mathrm{p}$.

2. Hugh Beale. Chitty on Contracts, 33rd Edition: Volume 1 (General Principles) [Читти о договорах: общие принципы]/Sweet \& Maxwell U.K., 2020.— 2561 p.

3. Jan M. Smits. Contract Law: A Comparative Introduction, 3rd Edition [Право договоров: сравнительное введение]/Edward Elgar Publishing, 2021. - 320 p.

4. John Cartwright. Contract Law: An Introduction to the English Law of Contract for the Civil Lawyer [Право договоров: введение в право договоров Великобритании для адвоката по гражданским делам]/Hart Publishing, 2016. - 513 p.

5. Lucy Jones. Introduction to Business Law, 5th Edition [Введение в предпринимательское право]/0xford University Press, 2019. — 640 p.

(с Козлов Антон Гордеевич ( antonkozlov3000@yandex.ru).

Журнал «Современная наука: актуальные проблемы теории и практики» 